\title{
Comparison of muscular strength and balance in athletes with visual impairment and hearing impairment
}

\author{
Bihter Akınoğlu1,*, Tuğba Kocahan² \\ 'Department of Physiotherapy and Rehabilitation, Faculty of Health Sciences, Ankara Yıldırım Beyazıt University, Ankara, Turkey \\ ${ }^{2}$ Department of Health Services, Sports General Directorship, The Ministry of Youth and Sports, Center of Athlete Training and Health Research, Ankara, Turkey
}

This study was conducted to compare muscular strength and balance of athletes with visual and hearing impairment. The study was carried out with 20 athletes of national Olympic level sports goalball team and 20 athletes of national Olympic level sports hearing-impaired karate team. Isokinetic muscular strength was assessed by IsoMed 2000 device as concentric-concentric at $60 \% \mathrm{sec}$ and $240 \% \mathrm{sec}$. Balance assessment was carried out with the Human Body Equilibrium 360 device. There was no significant difference between groups regarding age, height, weight and body mass index $(P>0.05)$. There were no differences between the dominant and nondominant knee flexion and extension peak torque (PT), \% of flexion/extension PT ratio, \% of dominant/nondominant PT differences at $60 \% \mathrm{sec}$ and $240 \%$ sec velocities $(P>0.05)$.
There was no difference between the groups regarding of both leg static balance $(P>0.05)$. However, single leg standing balance was significantly different between groups in favor of athletes with hearing impairment $(P<0.001)$. As a result of our study it was determined that muscular strength and static balance of athletes with visual and hearing impairment were similar, but athletes with visual problems are likely to have lower levels of single leg balance. Strategies to promote single leg balance in athletes with visual impairments are warranted.

Keywords: Balance, Disability, Goalball, Karate, Muscular strength, Sport

\section{INTRODUCTION}

Individuals with sensory impairments restrict from participating in physical activities and their physical activity level, muscular strength, cardiovascular endurance, balance, and sports performance are decreased (Akınoğlu and Nezire, 2018; Karakoc, 2016a; Karakoc, 2016b). However, sport activities improve the physical fitness and psychomotor abilities of these individuals, thereby enabling them to acquire the skills of daily living, orientation, and mobility (Yildirim et al., 2013).

Visual and hearing impairments are associated with increased risk of mortality in adulthood. One potential pathway explaining this association is reduced levels of physical activity across the lifespan (Rajala et al., 2000; Smith et al., 2015). A certain level of physical fitness is essential for the performance of sport-specific activities in many sport branches. Muscle strength which is one of the physical fitness parameters, is needed to outperform the competitor against the athlete (Clark and Mesch, 2016; Karakaya et al., 2009). Balance, the ability to maintain the equilibrium of the body, is maintained, controlled, and monitored by a multisensory system, consisting of the vestibular, visual and somatosensory system (Cohen, 2013; Grace Gaerlan et al., 2012). Adequate balance depends on the integration of these neurophysiological systems, the inadequacy of these systems negatively impact the balance (Wiszomirska et al., 2015). Vision and hearing ability are considered the most crucial sensory input in the process of maintaining postural control (Teasdale and Simoneau, 2001). Any impairment in visual perception and ability of hearing affects the maintaining of balance as a result of the damaged vestibular system and the deterioration of the connections between the neural structures in
${ }^{*}$ Corresponding author: Bihter Akınoğlu (i) https://orcid.org/0000-0002-8214-7895 Department of Physiotherapy and Rehabilitation, Faculty of Health Sciences, Ankara Yildırım Beyazit University, Ankara, Turkey

Tel: +90-312-305-1555, Fax: +90-312-596-7048, E-mail: rgkardelen@yahoo.com Received: June 13, 2018 / Accepted: August 10, 2018
This is an Open Access article distributed under the terms of the Creative Commons Attribution Non-Commercial License (http://creativecommons.org/licenses/by-nc/4.0/) which permits unrestricted non-commercial use, distribution, and reproduction in any medium, provided the original work is properly cited. 
the upper centers (Zebrowska et al., 2007).

Awareness about sports activities for persons with an impairment have increased over the years (Lieberman et al., 2002). Goalball has become most widely known team sport among the individuals with visual impairment (Lieberman et al., 2002). At the same time, individuals with hearing-impairment also participate in different kinds of sports such as karate (Lieberman et al., 2002). In both sport branches muscular strength and balance are crucial parameters for better performance (Clark and Mesch, 2016; Karakaya et al., 2009).

Although there are several studies investigating the muscular strength and balance of healthy group (Sculthorpe et al., 2017; Thomas et al., 2015) and athletes (Ambegaonkar et al., 2014; Hammami et al., 2016) there are very few studies comparing muscular strength and balance of athletes with visual and hearing impairment (Gawlik and Zwierzchowska, 2006). The aim of this study is to investigate whether there is any difference between muscular strength and balance of athletes with visual impairment and hearing-impairment and how the type of disabilities effect on these parameters.

\section{MATERIALS AND METHODS}

The study was conducted with the aim of comparing the knee flexion/extension isokinetic muscular strength and balance of athletes with visual impairment and hearing-impairment.

\section{Ethical clearance}

This study was designed according to the Declaration of Helsinki. All the athletes and coaches who accepted to participate in the study were fully informed about the study purpose, the assessments included in the study, the benefits of the study and all the athletes signed written informed consent.

\section{Setting}

Center of Athlete Training and Health Research.

\section{Participants}

The study was carried out with 20 (11 males and 9 females) athletes of national Olympic level sports goalball team (the visual impairment level is between the B1-B3) aged between 17-29 and 20 (11 males and 9 females) athletes of national Olympic level sports hearing-impaired karate team aged between 18-28 who complied with the inclusion criteria and voluntarily participated in the study. The inclusion criteria for the study included not hav- ing any systemic problem or any health problem except their impairment and having cooperation for testing. The potential benefits of the study are explained to athletes and communication with the athletes was provided by translators who fully fluent in both sign language and spoken language, also currently working with the team.

\section{Procedure}

\section{Isokinetic muscular strength assessment}

Isokinetic muscular strength was assessed by IsoMed 2000 (D. \& R. Ferstl GmbH, Hemau, Germany) device. Prior to the test, the athletes did structured warm-up protocol for $10 \mathrm{~min}$. Considering every athletes' anthropometric feature, the isokinetic device's setting was made following the warming. Joint angles were also set for the assessment by taking range of motion of the individuals into account. The assessment consisted of concentric-concentric knee flexion/extension movement between the angles of $90^{\circ}-10^{\circ}$ flexion. The assessment protocol: the athletes warmed with five repeats of the knee flexion/extension movement at $90 \% \mathrm{sec}$ for familiarization and comprehension of device mechanism. Following this, athletes performed 5 repeats of maximal knee flexion/extension movement at $60 \%$ sec and 15 repeats of maximal knee flexion/ extension movement at $240 \%$ sec velocity, the sequence of the angular velocity is chanced depending on their randomization. Athletes rested for $1 \mathrm{~min}$ between each angular velocity. The assessments were made bilaterally for each joint. First the dominant side was assessed and 3 min later the nondominant side was assessed. The dominant lower limb was defined by the athlete as the leg that was predominantly used to kick the ball (Chiou et al., 2013). The knee flexion and extension peak torque (PT), \% of flexion/extension PT ratio, \% of dominant/nondominant PT differences at $60 \%$ sec and $240 \%$ sec velocities were noted (Akınoğlu and Kocahan, 2017).

\section{Balance assessment}

Balance assessment was carried out with Human Body Equilibrium 360 (HUBER 360, LPG Systems, Middx, France). As balance tests, stability tests were evaluated how much a person can hold his position during $50 \mathrm{sec}$. During the test, the length and the area that athlete drew away from center line and speed parameters in these changes were determined. Single leg balance tests were also performed. During this test while athlete's one leg was positioned in knee flexion, other leg's which was on the ground, length and area measurement was determined in center changing period during $30 \mathrm{sec}$. 


\section{Statistical analysis}

All the data obtained from the measurements of athletes were analyzed with IBM SPSS Statistics ver. 22.0 (IBM Co., Armonk, NY, USA). Before analyzing the data, the Kolmogorov-Smirnov test was done to determine if the data was normally distributed or not. Because of our data did not show normal distribution, MannWhitney $U$-test was used to compare the muscular strength and balance values of athletes. The variables were calculated as means \pm standard deviation. The statistical significance was set at $P<0.05$.

Table 1. Demographic characteristics of the athletes who participated in the study

\begin{tabular}{lccc}
\hline Variable & $\begin{array}{c}\text { Goalball athletes } \\
(\mathrm{n}=20)\end{array}$ & $\begin{array}{c}\text { Karate athletes with } \\
\text { hearing impairment } \\
(\mathrm{n}=20)\end{array}$ & $P$-value \\
\hline Age $(\mathrm{yr})$ & $23.25 \pm 4.05$ & $22.30 \pm 2.71$ & 0.302 \\
Weight $(\mathrm{kg})$ & $71.80 \pm 13.74$ & $65.75 \pm 11.03$ & 0.144 \\
Height $(\mathrm{m})$ & $1.72 \pm 0.10$ & $1.69 \pm 0.08$ & 0.408 \\
Body mass index $\left(\mathrm{kg} / \mathrm{m}^{2}\right)$ & $23.92 \pm 2.55$ & $22.97 \pm 3.64$ & 0.144 \\
Sport years $(\mathrm{yr})$ & $11 \pm 3.37$ & $12.23 \pm 2.87$ & 0.132
\end{tabular}

Values are presented as mean \pm standard deviation.

alMann-Whitney U-test.

Table 2. Flexion and extension peak torque Vvlues, H/O ratio and dominant/ nondominant side strength ratio of the athletes

\begin{tabular}{|c|c|c|c|c|}
\hline Variable & $\begin{array}{l}\text { Angular } \\
\text { velocity }\end{array}$ & $\begin{array}{l}\text { Goalball } \\
\text { athletes } \\
(\mathrm{n}=20)\end{array}$ & $\begin{array}{l}\text { Karate athletes with } \\
\text { hearing impairment } \\
\qquad(n=20)\end{array}$ & $P$-value \\
\hline \multirow{2}{*}{$\begin{array}{l}\text { Flexion DM PT } \\
(\mathrm{N} / \mathrm{m})\end{array}$} & $60^{\circ} / \mathrm{sec}$ & $99.46 \pm 32.62$ & $91.18 \pm 29.87$ & 0.465 \\
\hline & $240^{\circ} / \mathrm{sec}$ & $81.42 \pm 27.52$ & $71.66 \pm 24.33$ & 0.262 \\
\hline \multirow{2}{*}{$\begin{array}{l}\text { Flexion NDM PT } \\
(\mathrm{N} / \mathrm{m})\end{array}$} & $60^{\circ} / \mathrm{sec}$ & $95.40 \pm 25.07$ & $91.95 \pm 34.56$ & 0.482 \\
\hline & $240^{\circ} / \mathrm{sec}$ & $80.51 \pm 24.82$ & $74.71 \pm 24.28$ & 0.499 \\
\hline \multirow{2}{*}{$\begin{array}{l}\text { Extension DM PT } \\
(\mathrm{N} / \mathrm{m})\end{array}$} & $60^{\circ} / \mathrm{sec}$ & $196.35 \pm 58.02$ & $163.36 \pm 42.82$ & 0.058 \\
\hline & $240^{\circ} / \mathrm{sec}$ & $125.22 \pm 37.38$ & $106.73 \pm 30.29$ & 0.066 \\
\hline \multirow{2}{*}{$\begin{array}{l}\text { Extension NDM PT } \\
(\mathrm{N} / \mathrm{m})\end{array}$} & $60^{\circ} / \mathrm{sec}$ & $192.02 \pm 59.73$ & $160.31 \pm 43.95$ & 0.102 \\
\hline & $240^{\circ} / \mathrm{sec}$ & $128.02 \pm 4$ & $108.32 \pm 30.93$ & 0.094 \\
\hline \multirow[t]{2}{*}{ H/Q ratio DM (\%) } & $60^{\circ} / \mathrm{sec}$ & $51.45 \pm 4$ & $13 \pm 5.32$ & 0.068 \\
\hline & $240^{\circ} / \mathrm{sec}$ & $64.64 \pm 8.60$ & $67.03 \pm 12.16$ & 0.441 \\
\hline \multirow[t]{2}{*}{$\mathrm{H} / \mathrm{O}$ ratio NDM (\%) } & $60^{\circ} / \mathrm{sec}$ & $51.07 \pm 7.49$ & $54.73 \pm 6.77$ & 0.057 \\
\hline & $240^{\circ} / \mathrm{sec}$ & $63.95 \pm 10.22$ & $69.32 \pm 12.12$ & 0.156 \\
\hline \multirow{2}{*}{$\begin{array}{l}\text { DM/NDM side } \\
\text { flexion (\%) }\end{array}$} & $60 \%$ sec & $103.40 \pm 15.35$ & \multicolumn{2}{|c|}{$101.13 \pm 11.29$} \\
\hline & $240^{\circ} / \mathrm{sec}$ & $100.66 \pm 12.67$ & \multicolumn{2}{|c|}{$95.62 \pm 15.92$} \\
\hline \multirow{2}{*}{$\begin{array}{l}\text { DM/NDM side } \\
\text { extension (\%) }\end{array}$} & $60^{\circ} / \mathrm{sec}$ & $103.22 \pm 10.10$ & \multicolumn{2}{|l|}{$102.44 \pm 9.30$} \\
\hline & $240^{\circ} / \mathrm{sec}$ & $99.26 \pm 11.25$ & \multicolumn{2}{|l|}{$98.50 \pm 6.43$} \\
\hline
\end{tabular}

Values are presented as mean \pm standard deviation.

DM, dominant side; NDM, nondominant side; $\mathrm{PT}$, peak torque; $\mathrm{H} / \mathrm{Q}$, Hamstring/Oadriceps ratio.

${ }^{\text {al } M a n n-W h i t n e y ~ U-t e s t . ~}$

\section{RESULTS}

There was no significant difference between groups regarding age, height, weight, and body mass index $(P>0.05)$ (Table 1$)$. Dominant-nondominant knee flexion and extension PT, $\%$ of flexion/extension PT ratio, \% muscular strength difference of dominant/nondominant side PT at $60 \%$ sec and $240 \%$ sec velocities were similar between the groups $(P>0.05)$. The athlete's flexion/ extension ratio was within normal limits on both sides at both angular velocities. When comparing knee flexion and extension movement between dominant and nondominant side there was no asymmetry in both groups and in both angular velocities (Table 2). When comparing stability evaluation in eyes opened and closed position, there was no difference between the groups' length and area parameters which athletes drew away from center line and speed parameters in these changes $(P>0.05)$. However single leg standing balance evaluation of right and left leg's length and area parameters were significantly different between groups in favor of athletes with hearing impairment $(P<0.001)$ (Table 3).

\section{DISCUSSION}

To the best of our knowledge, this is the first study to investigate whether there is any difference between muscular strength and balance of athletes with visual impairment and hearing impairment and how the type of disabilities effect on these parame-

Table 3. Balance measurement results of athletes

\begin{tabular}{lccc}
\hline Variable & $\begin{array}{c}\text { Goalball athletes } \\
(\mathrm{n}=20)\end{array}$ & $\begin{array}{c}\text { Karate athletes } \\
\text { with hearing } \\
\text { impairment }(\mathrm{n}=20)\end{array}$ & P-value ${ }^{\text {a) }}$ \\
\hline Eyes opened stability test & & & \\
Length $(\mathrm{mm})$ & $755.57 \pm 178.94$ & $767.08 \pm 391.27$ & 0.256 \\
Area $\left(\mathrm{mm}^{2}\right)$ & $485.56 \pm 101.62$ & $413.04 \pm 282.90$ & 0.914 \\
Speed $(\mathrm{mm} / \mathrm{sec})$ & $15.11 \pm 3.57$ & $15.34 \pm 7.82$ & 0.262 \\
Eyes closed stability test & & & \\
Length $(\mathrm{mm})$ & $794.14 \pm 246.71$ & $900.76 \pm 394.06$ & 0.387 \\
Area $\left(\mathrm{mm}^{2}\right)$ & $522.49 \pm 141.53$ & $435.40 \pm 121.12$ & 0.646 \\
Speed $(\mathrm{mm} / \mathrm{sec})$ & $15.88 \pm 4.93$ & $18.01 \pm 7.88$ & 0.387 \\
Dominant side single-leg & & & \\
Length $(\mathrm{mm})$ & $3,047.86 \pm 841.76$ & $1,881.69 \pm 629.02$ & $0.000^{* *}$ \\
Area $\left(\mathrm{mm}^{2}\right)$ & $4,662.06 \pm 794.29$ & $1,506.45 \pm 973.57$ & $0.000^{* *}$ \\
Nondominant side single-leg & & & \\
Length $(\mathrm{mm})$ & $3,116.66 \pm 1175.87$ & $1,865.11 \pm 579.87$ & $0.000^{* *}$ \\
Area $\left(\mathrm{mm}^{2}\right)$ & $7,017.58 \pm 1584.92$ & $1,531.82 \pm 640.10$ & $0.000^{* *}$
\end{tabular}

Values are presented as mean \pm standard deviation.

alMann-Whitney U-test. ${ }^{* *} P<0.01$. 
ters. As a result of our study, it was determined that muscular strength and static balance of athletes with visual and hearing impairment were similar, but athletes with visual impairments are likely to have lower levels of single leg balance.

In our study, isokinetic knee flexion - extension muscular strength at $60 \%$ sec and $240 \%$ sec angular velocity were found similar on both sides in athletes with visual and hearing impairment. Although there were several studies investigating the muscular strength and balance of healthy group and athletes, comparison of muscular strength and balance between athletes with visually and hearing impairment has not been made yet (Karakoc, 2016b).

It is also worth noting that studies concluded that agonist/antagonist muscular strength ratios of knee flexion and extension are important since their impairments makes athletes more prone to injury (Knapik et al., 1991). Previous studies have shown that this ratio should be $50 \%-60 \%$ at $60 \%$ sec velocity and $70 \%-80 \%$ at $240 \%$ sec velocity to prevent athletes injuring because of muscle imbalance (Kellis and Baltzopoulos, 1995; Osternig et al., 1983; Şahin, 2010). In our study, it was determined that this ratio was within normal limits at $60 \% \mathrm{sec}$ velocity but outside of normal limits at $240^{\circ} / \mathrm{sec}$ velocity in both groups. It could be concluded that there was a muscular strength imbalance against knee flexors in both athletes with visually and hearing impairment. The incidence of injury of athletes with visual and hearing impairment has been reported to as high as 78\% (Magno e Silva et al., 2013a; Weiler et al., 2016). Knee was found to be most common injured joint since $87 \%$ of these injuries were knee injuries (Magno E Silva et al., 2013b). Therefore, it seems reasonable to assume that muscle imbalance of the knee joint at the velocity of $240 \% \mathrm{sec}$ may be one of the predisposing factors in these frequent sport injuries. In this context, this finding can provide core information about group of athletes with visually and hearing impairment which has not yet been studied in detail.

Difference between the dominant and non-dominant muscular strength were also determined in our study. The study of Kannus (1994) concluded that $10 \%$ was upper limit of normal for this difference in isokinetic assessment. In our study, there was no asymmetry between the right and left knee flexion and extension at both $60 \%$ sec and $240 \%$ sec angular velocities in both groups. These findings were in agreement with previous studies in literature.

Adequate balance depends on the integration of multisensory system, consisting of the vestibular, visual and somatosensory system and the inadequacy of which negatively impact (Greve et al., 2013). Therefore, it wasn't surprising that severe hearing and vi- sual loss have been proven to have negative effects on balance and postural adjustment (Karakoc, 2016a; Karakoc, 2016b). Balance is not only an important factor to maintain postural control but achieve healthy body composition and physical fitness to successfully perform sportive activities. Balance is fundamental for dynamic sportive activities which require high speed and agility, but it is require for all kind of sports.

Atasavun Uysal et al. (2010) investigated the effect of loss of vision and hearing on gait and balance in 60 children, 20 of whom had hearing loss, 20 who were visually impaired, and 20 controls with no disability. The gait analysis was performed using a powdered surface while balance of participants was measured with standing balance subtests of the Southern California Sensory Integration Tests. As a result of the study, it was determined that the balance of children with visually and hearing impairment was different in favor of children with hearing impaired. That finding is consistent with our finding indicating that there was significant difference between groups of single leg balance in favor of athletes with hearing impairment. Conversely it was determined that there was no significant difference between groups in static balance in our study. Balance evaluations consisted of different protocols such as static-dynamic tests or with single-double leg. Single leg tests are more sensitive balance evaluation tests since the support surface is reduced. Evaluation with electronic devices which provide more objective data can be more informative about balance difference between groups. Therefore, we believe that significant difference in single leg balance, indifference in static balance in eyes opened-closed position in our study can be result of our objective measurement technique.

The perception of visual and auditory signals of external stimuli from different planes depends on the fact that all structures which are involved to maintain balance are healthy and fully developed (Sadowska et al., 2017). Most important problem in congenital blind individuals is the functional inadequacy of balance centers because of non-being able to perceive an external stimulus visually. Therefore, even if the vestibular system, proprioceptors and antigravity muscles are fully efficient, the absence of visual perceptions will have detrimental effect on the static standing balance or dynamic balance (Karakoc, 2016a; Karakoc, 2016b). In this way perception of vision helps individuals with hearing impairment to develop better motor skill model than visually impaired person. While the hearing-impaired group develops some vestibular compensation strategies for maintain and monitoring balance, fear of independent movement may have prevented the development of compensatory mechanisms in group visually impairment (Atasavun 
Uysal et al., 2010). In this regard, the results of our study coincided with the existing finding of the literature.

Several limitations need to be considered when interpreting the results of this research. One of them athletes with visual and hearing impairment were of different sports. Also, there was no control group to compare. Future studied should focus to compare different sport branches with same disabilities or different disabilities in same sport branches.

In conclusion, the number of people with disability who take part in sport has risen significantly. This study suggests that determination of the muscular strength imbalance and balance in individuals with disability will be a key stone in planning training program for these athletes. As a result of our study, we have determined that type of disabilities does not affect muscular strength. It was also found that athletes have strength imbalance against the endurance of the knee flexors. The single leg balance of athletes with visually and hearing impairment were different in favor of athletes with hearing impairment. We think that hamstring endurance training and balance training with the emphasis of single-leg exercises and should be integrated in the training program of both groups of athletes with visually and hearing impairment but especially for athletes with visually impairment.

\section{CONFLICT OF INTEREST}

No potential conflict of interest relevant to this article was reported.

\section{REFERENCES}

Akınoğlu B, Kocahan T. Characteristics of upper extremity's muscle strength in Turkish national wheelchair basketball players team. J Exerc Rehabil 2017;13:62-67.

Akınoğlu B, Nezire K. Determination of physical fitness level in children with hemiparetic and diparetic cerebral palsy. Turkish J Physiother Rehabil 2018;29:11-18.

Ambegaonkar JP, Mettinger LM, Caswell SV, Burtt A, Cortes N. Relationships between core endurance, hip strength, and balance in collegiate female athletes. Int J Sports Phys Ther 2014;9:604-616.

Atasavun Uysal S, Erden Z, Akbayrak T, Demirtürk F. Comparison of balance and gait in visually or hearing impaired children. Percept Mot Skills 2010;111:71-80.

Chiou SY, Wang RY, Liao KK, Yang YR. Homologous muscle contraction during unilateral movement does not show a dominant effect on leg representation of the ipsilateral primary motor cortex. PLoS One 2013; 8:e72231.

Clark B, Mesch J. A global perspective on disparity of gender and disability for deaf female athletes. Sport Society 2016;1:1-12.

Cohen $\mathrm{AH}$. Vision rehabilitation for visual-vestibular dysfunction: the role of the neuro-optometrist. NeuroRehabilitation 2013;32:483-492.

Gawlik K, Zwierzchowska A. A comparison of chosen strength abilities in deaf and blind adolescents. J Hum Kinet 2006;15:97-101.

Grace Gaerlan M, Alpert PT, Cross C, Louis M, Kowalski S. Postural balance in young adults: the role of visual, vestibular and somatosensory systems. J Am Acad Nurse Pract 2012;24:375-381.

Greve JM, Cuğ M, Dülgeroğlu D, Brech GC, Alonso AC. Relationship between anthropometric factors, gender, and balance under unstable conditions in young adults. Biomed Res Int 2013;2013:850424.

Hammami R, Chaouachi A, Makhlouf I, Granacher U, Behm DG. Associations between balance and muscle strength, power performance in male youth athletes of different maturity status. Pediatr Exerc Sci 2016; 28:521-534.

Kannus P. Isokinetic evaluation of muscular performance: implications for muscle testing and rehabilitation. Int J Sports Med 1994;15 Suppl 1:S11-18.

Karakaya IC, Aki E, Ergun N. Physical fitness of visually impaired adolescent goalball players. Percept Mot Skills 2009;108:129-136.

Karakoc O. Muscle strength and flexibility without and with visual impairments judoka's. Int Educ Stud 2016a;9:12-17.

Karakoc O. The investigation of physical performance status of visually and hearing impaired applying judo training program. J Educ Train Stud 2016b;4:10-17.

Kellis E, Baltzopoulos V. Isokinetic eccentric exercise. Sports Med 1995;19: 202-222.

Knapik JJ, Bauman CL, Jones BH, Harris JM, Vaughan L. Preseason strength and flexibility imbalances associated with athletic injuries in female collegiate athletes. Am J Sports Med 1991;19:76-81.

Lieberman LJ, Houston-Wilson C, Kozub FM. Perceived barriers to including students with visual impairments in general physical education. Adapt Phys Activ Q 2002;19:364-377.

Magno e Silva M, Bilzon J, Duarte E, Gorla J, Vital R. Sport injuries in elite paralympic swimmers with visual impairment. J Athl Train 2013a;48: 493-498.

Magno E Silva MP, Winckler C, Costa E Silva AA, Bilzon J, Duarte E. Sports injuries in paralympic track and field athletes with visual impairment. Med Sci Sports Exerc 2013b;45:908-913.

Osternig LR, Hamill J, Sawhill JA, Bates BT. Influence of torque and limb speed on power production in isokinetic exercise. Am J Phys Med 1983; 62:163-171

Rajala U, Pajunpää H, Koskela P, Keinänen-Kiukaanniemi S. High cardio- 
vascular disease mortality in subjects with visual impairment caused by diabetic retinopathy. Diabetes Care 2000;23:957-961.

Sadowska D, Stemplewski R, Szeklicki R. Postural control in young people with visual impairments and various risks of falls. J Vis Impair Blind 2017;111:261-270.

Şahin Ö. Isokinetic measurements in rehabilitation. Cumhur Med J 2010; 32:386-396.

Sculthorpe NF, Herbert P, Grace F. One session of high-intensity interval training (HIIT) every 5 days, improves muscle power but not static balance in lifelong sedentary ageing men: a randomized controlled trial. Medicine (Baltimore) 2017;96:e6040.

Smith L, Gardner B, Fisher A, Hamer M. Patterns and correlates of physical activity behaviour over 10 years in older adults: prospective analyses from the English Longitudinal Study of Ageing. BMJ Open 2015;5: e007423.

Teasdale N, Simoneau M. Attentional demands for postural control: the effects of aging and sensory reintegration. Gait Posture 2001;14:203-210.
Thomas E, Bianco A, Bellafiore M, Battaglia G, Paoli A, Palma A. Determination of a strength index for upper body local endurance strength in sedentary individuals: a cross sectional analysis. Springerplus 2015;4: 734.

Weiler R, Van Mechelen W, Fuller C, Verhagen E. Sport injuries sustained by athletes with disability: a systematic review. Sports Med 2016;46: 1141-1153.

Wiszomirska I, Kaczmarczyk K, Błażkiewicz M, Wit A. The impact of a vestibular-stimulating exercise regime on postural stability in people with visual impairment. Biomed Res Int 2015;2015:136969.

Yildirim S, Yuksel R, Doganay S, Gul M, Bingol F, Dane S. The benefits of regular physical activity on hearing in visually impaired adolescents. Eur J Basic Med Sci 2013;3:17-21.

Zebrowska A, Gawlik K, Zwierzchowska A. Spirometric measurements and physical efficiency in children and adolescents with hearing and visual impairments. J Physiol Pharmacol 2007;58 Suppl 5(Pt 2):847857. 